\title{
The influence of erythropoietin on apoptosis and fibrosis in the early phase of chronic pancreatitis in rats
}

\author{
Weronika Kazmierak ${ }^{1}$, Agnieszka Korolczuk², Jacek Kurzepa ${ }^{3}$, Grażyna Czechowska ${ }^{1}$, \\ Anna Boguszewska-Czubara ${ }^{3}$, Agnieszka Madro ${ }^{1}$
}

\begin{abstract}
${ }^{1}$ Department of Gastroenterology with Endoscopic Unit, Medical University of Lublin, Lublin, Poland

2Department of Clinical Pathomorphology, Medical University of Lublin, Lublin, Poland ${ }^{3}$ Department of Medicinal Chemistry, Medical University of Lublin, Lublin, Poland
\end{abstract}

Submitted: 10 January 2018; Accepted: 1 August 2018

Online publication: 12 October 2020

Arch Med Sci 2021; 17 (4): 1100-1108

DOI: https://doi.org/10.5114/aoms.2020.99800

Copyright (c) 2020 Termedia \& Banach

\section{Abstract}

Introduction: Chronic pancreatitis (CP) is a continuing, inflammatory process of the pancreas, characterised by irreversible morphological changes. The identification of pancreatic stellate cells resulted in the development of research on the pathogenesis of CP. Erythropoietin (Epo) regulates the interaction between apoptosis and inflammation of the brain, kidney, and heart muscle. Erythropoietin receptors were also found in the pancreas, in particular on the islet cells. Our objective was to evaluate the influence of Epo on fibrosis and apoptosis in experimental CP.

Material and methods: The experiments were performed on 48 male Wistar rats (250-350 g). The animals were divided into six equal groups (I - control, II - chronic cerulein - induced pancreatitis, III - $1 \mathrm{ml}$ of Epo sc, IV $-0.5 \mathrm{ml}$ of Epo sc, V - CP treated with $1 \mathrm{ml}$ Epo, VI - CP treated with $0.5 \mathrm{ml}$ Epo). The blood for gelatinases and pancreata for the morphological examinations and immunohistochemistry were collected.

Results: A slight reduction of interstitial oedema and less severe fibrosis were noticed in the groups treated with Epo. Reduced expression of caspase- 3 and $\alpha$-actin, and a lack of Bcl- 2 expression were observed in areas with inflammation. There was no expression of caspase- 9 observed in all groups. There were no statistically significant differences between the groups in the activity of gelatinases.

Conclusions: Erythropoietin seems to have the effect of reducing fibrosis and apoptosis in an experimental model of CP.

Key words: fibrosis, chronic pancreatitis, apoptosis, erythropoietin, gelatinases.

\section{Introduction}

In recent years, all over the world rapidly increasing incidence and mortality caused by diseases of the pancreas can be seen. The average annual incidence of chronic pancreatitis (CP) among the European population is between 6 and 7 cases per 100,000 population, while in Poland there are 5 cases per year per 100,000 residents [1-3]. However, the highest number of cases has been observed recently in Asian countries.

\author{
Corresponding author: \\ Weronika Kazmierak \\ Department of \\ Gastroenterology with \\ Endoscopic Unit \\ Medical University of Lublin \\ 8 Jaczewskiego St \\ 20-954 Lublin, Poland \\ Phone: +48 817244533 \\ E-mail: weronika.kazmierak@ \\ gmail.com
}


In southern India it reaches as much as 114200/100,000 inhabitants [4], while in Japan, it is $36.9 / 100,000$ population [5].

Chronic pancreatitis is a continuing, inflammatory process of the pancreas, characterised by irreversible morphological changes. In severe cases of $\mathrm{CP}$ the processes of fibrosis and calcification, extension of the pancreatic duct, and progressive failure of exocrine and endocrine pancreatic function are observed [6]. In the most cases, the primary aetiological factor of CP is the excessive consumption of alcohol (about $70 \%$ of cases) [7]. It is believed that a daily dose $150 \mathrm{~g}$ of alcohol within 5-15 years leads to the development of CP in $3-10 \%$ of alcoholics [8].

The pathogenesis of CP has not been definitively clarified yet. The hypothesis that best explains the pathogenesis of $C P$, is the theory of SAPE (sentinel acute pancreatitis event) proposed by D.C. Whitcomb. This hypothesis combines the theories of oxidative stress, and metabolic and necrosis-fibrosis, assuming that the first episode of acute pancreatitis is a warning of development of CP. Subsequent episodes meet the already sensitised and activated stellate cells, which leads to fibrosis and damage of the acinar cells of the pancreas by acute inflammation [9].

The identification of pancreatic stellate cells has led to the development of research into the pathogenesis of CP [10]. The first information about the presence of cells rich in vitamin $A$ in the pancreas appeared in 1982. They were observed for the first time by N. Watari in mice fed with an excess of vitamin A [11].

In the course of CP fibrosis is a commonly described morphological change. It is a dynamic process and potentially reversible in the early phases of the disease. It should be also emphasised that Mews studied the effect of cytokines that are important in the development of CP: tumour necrosis factor $\alpha$ (TNF- $\alpha$ ) and interleukins (IL)-1, IL-6, and IL-10. Further research has showed more stellate cell activators: platelet-derived growth factor (PDGF), transforming growth factor $\beta 1$ (TGF- $\beta 1$ ), and angiotensin II - the free oxygen radicals $[12,13]$. These substances induce the development of inflammation and activation of stellate cells, which become myofibroblasts $[14,15]$. They are able to migrate, proliferate, and produce the extracellular matrix and its components such as collagen, laminin, fibronectin, and matrix metalloproteinases (MMPs) and their inhibitors (TIMPs) [16]. These processes are accompanied by loss of vitamin A drops and increased expression of the protein $\alpha$-smooth muscle actin ( $\alpha$-SMA) [17].

Fibrosis, which is a constant component of CP, is observed in a variety diseases besides gastrointestinal tract, such as idiopathic pulmonary fibro- sis, cystic fibrosis [18], hypertrophic cardiomyopathy [19], glomerulonephritis [20], and others.

The intensity of fibrosis depends on the production of extracellular matrix components and their degradation by MMPs [21]. Two MMP gelatinases (MMP-2 and MMP-9) play the most important role in inflammatory processes because of their ability to degrade type IV collagen [22].

It is also believed that apoptosis plays a major role in $\mathrm{CP}$, leading to a reduction of acinar cells and pancreatic islet cells, which in turn may lead to disruption of endo- and exocrine function. Apoptosis plays an important role in the development of tissues and maintenance of their homeostasis, is involved in the processes of embryogenesis and the aging of cells, and is responsible for the removal of damaged cells. Among the main effectors of apoptosis are caspases, especially caspase-3, which plays an key role in linking the outer and inner way of promoting apoptosis [23].

Erythropoietin (Epo) is a glycoprotein hormone that stimulates the various stages of erythropoiesis and increases red blood cell production by bone marrow. It is produced by the foetal liver and kidney after birth [24]. There are a number of reports emphasising the ability of Epo to regulate the interaction between apoptosis and inflammation in the brain [25], kidney [26], small intestine [27], or myocardium [28]. Erythropoietin receptors were also found in the pancreas, in particular on the islet cells $[29,30]$. Little is known about the impact of Epo on pancreatic cells and fibrosis.

Our objective was to evaluate the influence of Epo on fibrosis and apoptosis in experimental CP.

\section{Material and methods}

\section{Animals}

The experiment was performed on 48 male Wistar rats (250-350 g). The animals were kept in standard animal laboratories, and food and water were provided. The experiments were carried out under the same conditions. The Bioethical Board of the Medical University of Lublin Local Ethics Committee on Animal Experiments approved the protocol of the study (No. 19/2012 - 18.05.2012).

The animals were divided into six equal groups ( I - control - 0.9\% NaCl $0.1 \mathrm{ml}$, intraperitoneally, every hour for $6 \mathrm{~h}$, three times per week for 4 weeks; II - chronic cerulein (Sigma-Aldrich, Poole, Dor set, UK)-induced pancreatitis $-50 \mu \mathrm{g} / \mathrm{kg}$ every hour for $6 \mathrm{~h}$, three times per week for 4 weeks intraperitoneally; III - Epo (Sigma-Aldrich, Poole, Dorset, UK) sc (five doses - $1 \mathrm{ml}$ Epo diluted in $0.1 \mathrm{ml}$ sialin solution - Baxter, Poland/day); IV - Epo sc (five doses - $0.5 \mathrm{ml}$ Epo diluted in 0.1 sialin solution - Baxter, Poland/day); V - CP treated with $1 \mathrm{ml}$ Epo, $\mathrm{VI}-\mathrm{CP}$ treated with $0.5 \mathrm{ml}$ 
Epo). The survival rate of animals in all groups was $100 \%$. The animals were euthanised and sacrificed after $24 \mathrm{~h}$ from the administration of the last doses. The serum was transferred for further analysis, and pancreata were collected for the morphological examinations and immunohistochemistry.

\section{Biochemical assays}

MMP-2 and MMP-9 activities in serum were determined with gelatine zymography. The separation of the samples was done on a $10 \%$ polyacrylamide gel with $0.05 \%$ gelatine type $A$ from porcine skin (Sigma-Aldrich, Poole, Dorset, UK). Gels were stained with $0.1 \%$ Coomassie Blue R-250 in 30\% ethanol and 10\% acetic acid and destined in 30\% ethanol and 10\% acetic acid. MMP-2 and MMP-9 activity was detected as clear bands on the blue background.

Enzymes were identified by comparing their migration pattern with a molecular mass standard (Fermentas, SM0441), and MMP-2 and MMP-9 standards (R\&D Systems, Minneapolis, Minnesota, USA).

\section{Histology}

Pancreata sections for histopathology were collected and were placed in $10 \%$ buffered formalin ( $\mathrm{pH} \mathrm{7.4).} \mathrm{The} \mathrm{samples} \mathrm{were} \mathrm{embedded} \mathrm{in}$ paraffin blocks. Sections were cut on the microtome and stained with haematoxylin and eosin $(\mathrm{H}+\mathrm{E})$ [31] and Masson's Trichrome. The slides were evaluated under a light microscope by an experienced pathologist. Sections were evaluated for the presence and severity of inflammation and fibrosis. Furthermore, the presence of degenerative lesions including vacuolar degeneration and oedema was also evaluated.

Histological changes of the pancreas were classified, based on the approximate percentage of acinar cells showing vacuolisation and oedema,

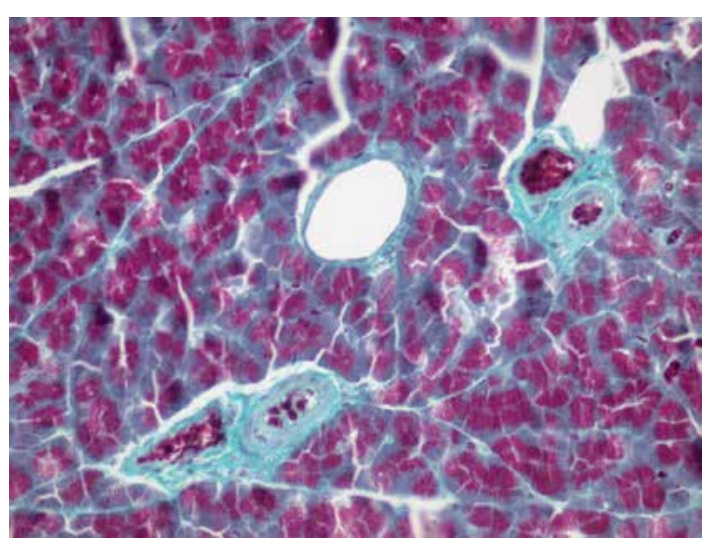

Figure 1. Control group. $\mathrm{H}+\mathrm{E}$. Correct microscopic image of exocrine pancreas. $400 x$ and the areas showing inflammatory cell infiltration and fibrosis: $0=$ absent, $1=<5 \%, 2=5-25 \%$, $3=25-50 \%, 4=>50 \%$ (Satoh scale).

\section{Immunohistochemistry}

Paraffin blocks were cut in a microtome into sections of 4 microns, and incubated for $24 \mathrm{~h}$ at $58^{\circ} \mathrm{C}$. Sections were deparaffinised in a series of xylene and then passed through a decreasing series of ethyl alcohol $(100 \%, 90 \%, 60 \%)$ to distilled water. Antigens for anti- $\alpha$-actin (small bowel tissue) were exposed in the device DAKO-PT Link Pre-Treatment Module for Tissue Specimens, catalogue number PT 101. Antigens Bcl-2(tonsil tissue) were exposed in the DAKO-PT Link Pre-Treatment Module for Tissue Specimens device catalogue number PT 101. Antigens for caspase-3 (brain tissue) were unveiled in the DAKO-PT Link, Pre-Treatment Module for Tissue Specimens device catalogue number PT 101. Antigens for caspase-9 (small bowel tissue) buffer were heated in DAKO Envision FLEC-Target Retrieval Solution $\mathrm{pH}$ low (50x) catalogue number K8008 for $40 \mathrm{~min}$. Sections were placed in a Dako Wash Buffer. Sections were incubated with primary antibodies. The slides were evaluated under a light microscope by an experienced pathologist.

\section{Statistical analysis}

The differences between the control group and groups receiving Epo were compared (Satoh's scale). The activity of gelatinases was expressed as the optical density of the substrate lysis zone and arithmetic mean. Quantification of zymograms was performed using a computer scanner (1200 dpi). Statistically significant values were considered when $p<0.05[32,33]$. Statistical analysis was performed with the use of the computer-assisted statistical software ImageJ $1.42 \mathrm{q}$ (National Institutes of Health, Bethesda, MD, USA).

\section{Results}

In the group receiving cerulein injections (II), intensification of fibrosis around the pancreatic ducts was observed. Interstitial oedema and vacuolar degeneration were also noticed (Figure 1). Comparably, a slight reduction of interstitial oedema and less severe fibrosis were reported in the groups treated with Epo (Figure 2). In the control group and in both groups treated with Epo no morphological changes were observed (Figure 3).

The intensity of morphological changes according to the Satoh scale [34] are presented in Table I. The changes were evaluated according to the following scale: 0 - no change, $1<5 \%, 2-5-25 \%$, $3-25-50 \%, 4>50 \%$ tissue involvement. 


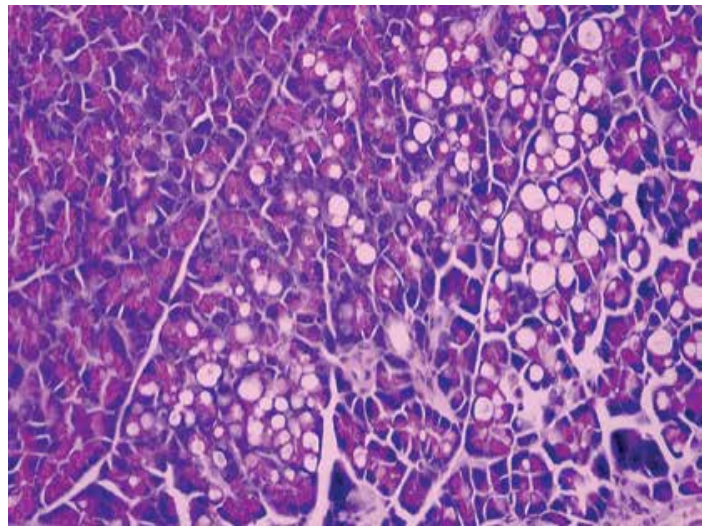

Figure 2. Group II. Converging vacuoles in the cytoplasm of numerous follicular cells. $400 x$

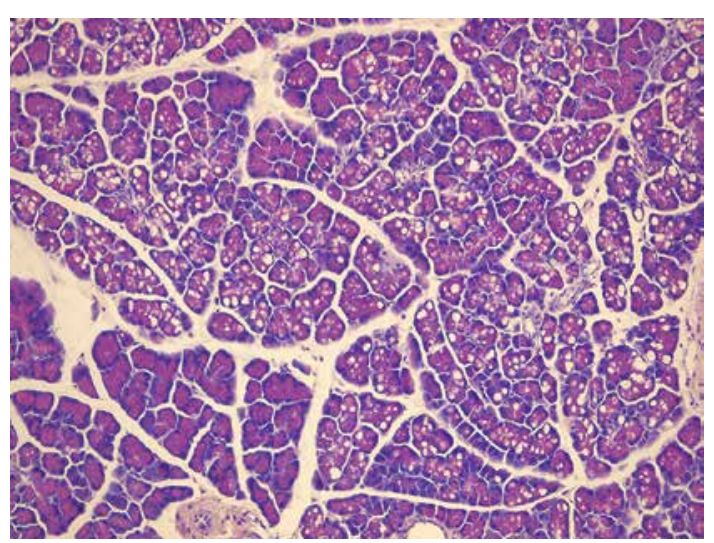

Figure 3. Group II. Vacuolar degeneration in the cytoplasm of numerous follicular cells. 200x

Table I. The intensity of morphological changes in the studied groups according to the Satoh scale

\begin{tabular}{|lccccc|}
\hline Group & \multicolumn{5}{c}{ Type of change } \\
\cline { 2 - 6 } & Inflammation & Fibrosis & Vacuolisation & Oedema & $\begin{array}{c}\text { Extension of } \\
\text { pancreatic ducts }\end{array}$ \\
\hline I & 0 & 0 & 0 & 0 & 0 \\
\hline II & 3 & 2 & 2 & 3 & 2 \\
\hline III & 0 & 0 & 1 & 0 & 0 \\
\hline IV & 0 & 0 & 2 & 0 & 0 \\
\hline V & 1 & 1 & 1 & 2 & 1 \\
\hline VI & 1 & 1 & & 2 & 1 \\
\hline
\end{tabular}

\section{Immunohistochemistry}

In group II, a strong expression of $\alpha$-actin was noticed in damaged acinar cells and in cells with vacuolar degeneration (Figure 4). The $\alpha$-actin expression appeared focally in groups $\mathrm{V}$ and $\mathrm{VI}$, mostly in cells with vacuolar degeneration, and it was not visible in cells with inflammatory changes (Figure 5).

In group II there was a very weak expression of $\mathrm{Bcl}-2$ in acinar cells (Figure 6), while in the other groups there was no expression noted (Figure 7).

In group II cytoplasmic expression of caspase-3 was observed in the acinar cells, especially in the

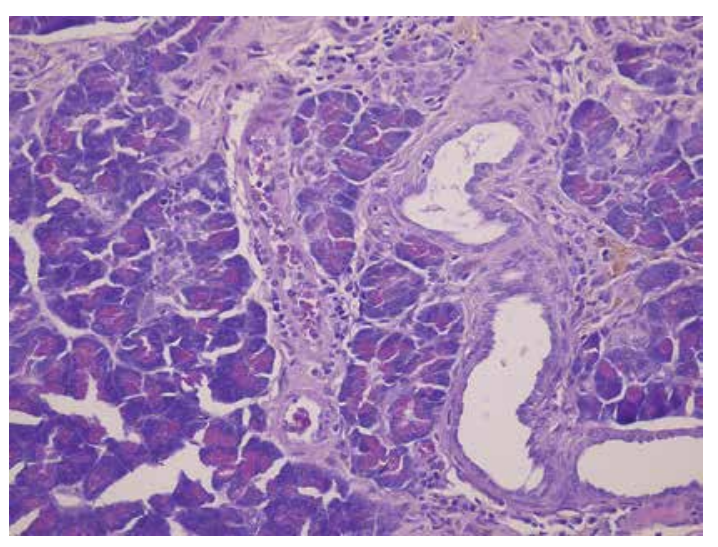

Figure 4. Group II. H + E. Fibrosis around the pancreatic ducts and interstitial oedema and vacuolar degeneration. $400 x$ inflammatory changes and the cells with vacuolar degeneration (Figure 8). In groups $\mathrm{V}$ and $\mathrm{VI}$ a reduced expression of caspase- 3 was observed in areas with inflammation. In the cells with vacuolar degeneration, a weak, focal expression was noticed (Figure 9). The expression of caspase-9 was not observed in any of the groups.

\section{Biochemistry}

The serum zymography revealed the presence of several gelatinolytic activities, including the corresponding pro-MMP-2 (72 kDa), pro-MMP-9

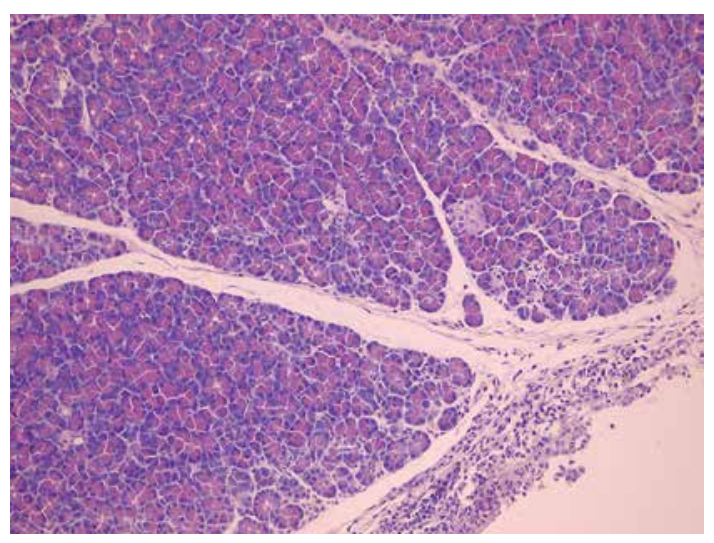

Figure 5. Group III. H + E. Slightly increased inflammatory infiltration - mainly lymphocytes and fewer plasmocytes in peripancreatic tissue. 200x 


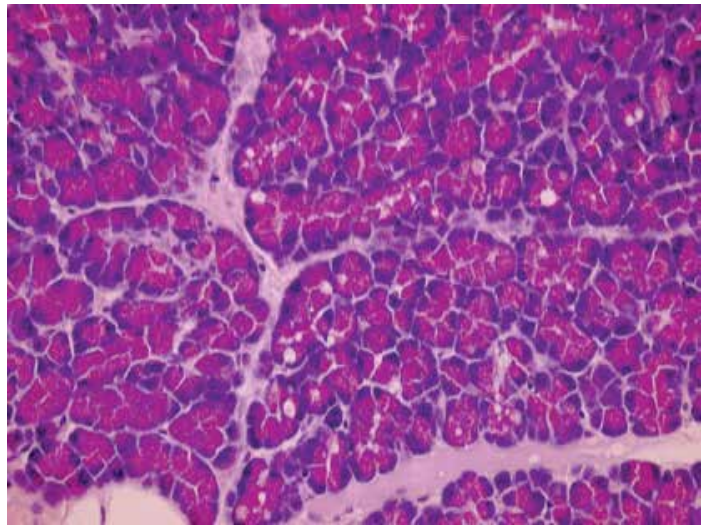

Figure 6. Group VI. Focal vacuolar degeneration of the cytoplasm of pancreatic cells. $400 x$

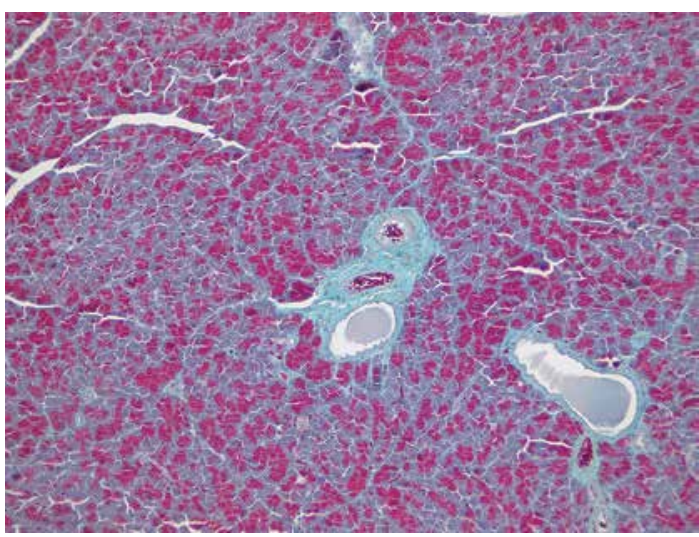

Figure 8. Group V. Focal, slightly increased perivascular fibrosis. $400 \times$

(92 kDa), and active forms of MMP-9. For the calculations MMP-9 activity was expressed as the sum of two forms: weights $92 \mathrm{kDa}$ and $85 \mathrm{kDa}$. The highest MMP-9 activity was observed in both groups of rats treated with cerulein (group II) and Epo (group III and group IV). The differences measured by ANOVA test did not reach statistical significance $(p=0.096)$. However, the t-test showed a statistical difference between MMP-9 activity in group I vs. group V $(p=0.013)$ and between group I vs. group VI $(p=0.003)$. No statistically significant fluctuations between the activities of MMP-2 serum were observed in all groups. ( $p=0.987)$. The results are shown in the representative zymogram (Figure 10) and in Tables II and III.

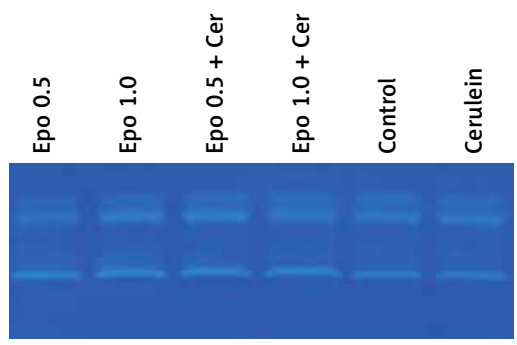

Pro-MMP-9 (92 kDa) MMP-9 (85 kDa)

Pro-MMP-2 (72 kDa)

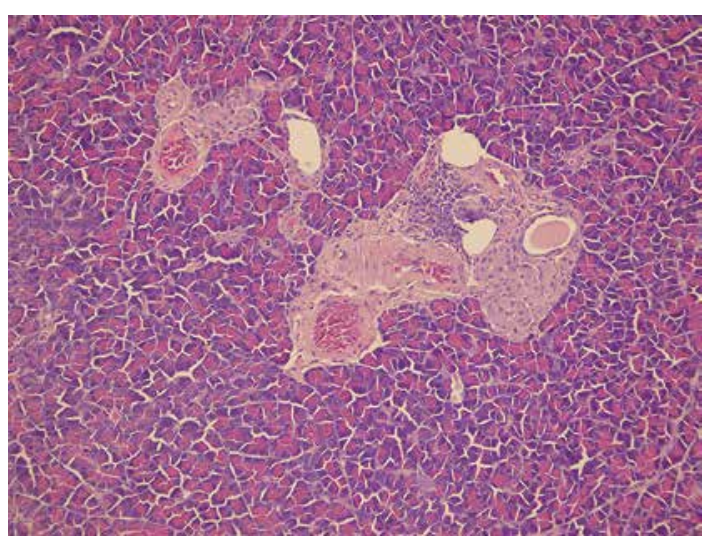

Figure 7. Group V. H + E. Reduction of interstitial oedema and less severe fibrosis around the pancreatic ducts. $200 \times$

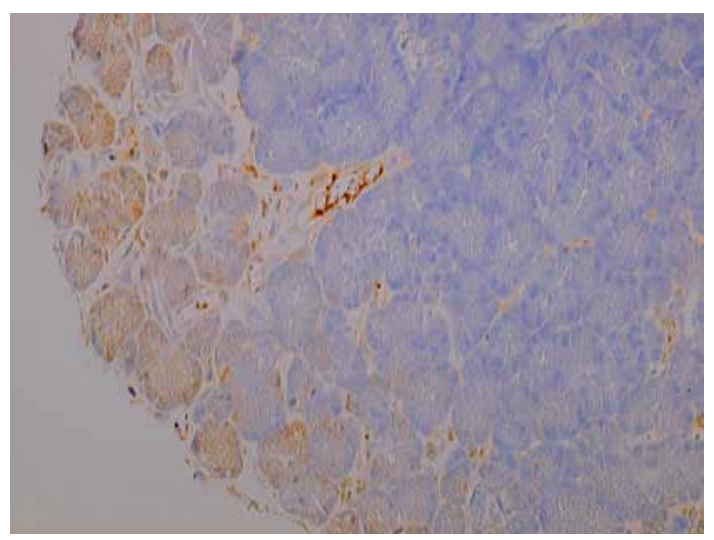

Figure 9. Group VI. A reduced expression of caspase- 3 was observed in areas with inflammation. $400 x$

\section{Discussion}

Chronic pancreatitis is a disease for which the pathophysiological mechanism, despite the discovery of new dependencies, remains unclear. There have been a number of experimental and clinical studies that have resulted in a new perspective of the aetiology of CP. Recently, there has been an increased interest in Epo and its impact on the course of certain diseases. So far, there has not been much research on the effects of Epo on the pancreas. There are few data on the effect of Epo on pancreatic cells and fibrosis, hence the lack of opportunities to discuss the results of the experiment with other authors.

\section{The effect of erythropoietin in cardiovascular diseases}

There are numerous reports emphasising the ability of Epo to regulate the interaction between apoptosis and inflammation. The authors underline the cytoprotective role of Epo in experimental tissue damage [35]. So far, the best-known beneficial effects of Epo are on the myocardium. Smith et al. emphasised the occurrence of EpoR 
Table II. MMP-9 activity in the serum

\begin{tabular}{|lccccccc|}
\hline Parameter & Group I & Group II & Group III & Group IV & Group V & Group VI & ANOVA \\
\hline Optical density & 118.9 & 125.0 & 121.1 & 120.7 & 145.4 & 133.8 & $p=0.096$ \\
\hline Standard deviation & 7.8 & 13.5 & 30.4 & 25.0 & 25.3 & 9.1 & \\
\hline
\end{tabular}

Table III. MMP-2 activity in the serum

\begin{tabular}{|lccccccc|}
\hline Parameter & Group I & Group II & Group III & Group IV & Group V & Group VI & ANOVA \\
\hline Optical density & 82.6 & 85.3 & 86.1 & 85.6 & 88.2 & 90.5 & $p=0.987$ \\
\hline Standard deviation & 19.6 & 22.0 & 22.7 & 20.4 & 24.0 & 22.3 & \\
\hline
\end{tabular}

receptor in vascular endothelial cells, smooth muscle cells, and cardiomyocytes. The authors underlined that reperfusion of ischaemic myocardium may limit the area of necrosis without affecting the number of apoptotic cells. Also released at that time, free radicals and increased intracellular calcium levels favour this process [36]. It seems that the reduction of cardiomyocyte apoptosis during ischaemia and reperfusion may result in a decrease in the cardiomyocyte apoptosis and, consequently, inhibit the development of post-infarction heart failure [37]. There are also an increasing number of in vivo studies conducted on adult rats and evaluating the effects of Epo on ischaemia and reperfusion. Cai pointed out that EpoRh administration improved the left ventricular performance, reduced the number of apoptotic cells, and decreased caspase- 3 expression in cells. At the same time, they did not reach the effect of improving coronary blood flow [38].

Similar results were also obtained in experimental models of ischaemic stroke. The fact that the astrocytes are able to produce Epo was used. Ruscher in his research showed the protective effect of Epo on neurons before their death induced by glutamate [39].

\section{The neuroprotective effects of erythropoietin}

The neuroprotective effects of Epo in animal models of cerebral ischaemia were also shown. The stimulation of neurogenesis and improvement of brain function after Epo administration was observed by researchers [40]. Jerndal conducted a meta-analysis of 19 studies of animal models of the ischaemic central nervous system. They confirmed the neuroprotective effect of Epo and drew attention to the decrease of ischaemia and improvement of brain function after Epo administration [41]. Ugurluer evaluated the effect of Epo against oxidant injury following brain radiotherapy in experimental model. He showed a positive neuroprotective effect of Epo connected with decreasing free radical production and increasing expression of antioxidant enzymes [42].
It should also be emphasised that there are clinical trials conducted on patients with ischaemic stroke [43]. During phase II of the study, there were no complications associated with the administration of Epo, while the protective effects of stroke were observed [44]. However, in phase III of the study, which was conducted as a double-blind test, with the presence of the control group, better results were not confirmed in groups treated with Epo as compared with the control group. Higher mortality was recorded in the groups treated with Epo [45].

\section{The effect of erythropoietin on the gastrointestinal tract}

There are few studies regarding the influence of Epo on the gastrointestinal tract, but there are some reports on the effects of Epo on the liver damage caused by ischaemia and reperfusion. Sepodes administered Epo to rats intravenously at a dose of $100 \mathrm{U} / \mathrm{kg}$ and held hepatic ischaemia for $30 \mathrm{~min}$ followed by $2 \mathrm{~h}$ of reperfusion. The researchers found that the use of Epo 5 min before the hypoxia resulted in a decrease in transaminase levels and the reduction of caspase- 3 expression, which led to apoptosis inhibition [46]. Protective effects of Epo on liver cells were also evaluated by Schmedinga. They showed that administration of Epo 45 min before inducing ischaemia significantly reduced the activity of transaminases and inhibited apoptosis [47]. It is worth emphasising that in our department we examined the effects of Epo activity of gelatinases in the course of galactosamine-induced liver damage in rats. It has been found that administration of Epo before injection of galactosamine caused a decrease in MMP-2 and MMP-9. It can therefore be concluded that Epo may have a hepatoprotective effect, influencing the process of fibrosis and organ damage [48].

Moreover, in recent years there have been reports on the effects of Epo on the course of acute pancreatitis (AP). Ukan estimated levels of interleukin in rats with taurocholate-induced acute pancreatitis. The researchers found that intramus- 
cular administration of Epo significantly lowers the level of interleukin IL-6 [49].

Currently, there are first reports emphasising the role of Epo in preventing the development of diabetes. Researchers have used the existence of receptors for Epo in islet cells, and they demonstrated a cytoprotective role in some experimental models of diseases. Craig et al. [50] and Thomas [51] drew attention to the shortage of Epo and a higher incidence of anaemia in selected patients with diabetes, suggesting a potential positive effect of the use of Epo in the prevention of diabetes.

Choi et al. in 2010 presented the results of research on the effects of Epo administered to mice with type 1 diabetes and type 2 induced by streptozotocin. Positive effects on prevention of diabetes were found in both cases. It seems that this effect is achieved by direct action of Epo on the $\beta$ islet cells, leading to an anti-apoptotic effect, proliferation, and angiogenesis. On the other hand, it does not affect the function of the $\beta$-cells. The researchers also pointed out the lack of a visible reduction in the level of glucose in mice, suggesting a positive effect of Epo on the $\beta$-cell secretion and maintenance of glucose balance [52].

There are also reports about a potential positive role of Epo for reducing the progression of diabetic nephropathy induced by streptozotocin in an experimental rat model. The researchers noticed higher creatinine clearance and lower mean albumin-to-creatinine ratio in groups treated with Epo than in the diabetic rats. Also, tubulointerstitial inflammation and interstitial fibrosis were lower in the treated groups [53].

In the literature there are only a few reports on the effects of Epo on the process of fibrosis. Chen et al. conducted experiments to assess the effect of Epo on heart fibrosis induced by doxorubicin. They evaluated levels of MMP-2 and TIMP-2 and performed histological examinations. They found that the administration of Epo decreased MMP-2 activity and increased the level of inhibitor TIMP2. The authors conclude that Epo may influence a balance between MMPs and TIMPs and may inhibit extracellular matrix degradation. It may also reduce the risk of myocardial injury [54]. On the other hand, Pawlak in his study on the effects of Epo on the activity of the metalloproteinases in haemodialysis patients showed that chronic use of the drug does not affect MMP activity and severity of inflammation. He showed no differences in the concentrations of metalloproteinases in different groups of patients [55].

After analysing all the presented studies, it can be assumed that the use of Epo in the case of many diseases may increase tolerance to organ damage and hypoxia by inhibiting caspase cascade, leading to a reduction of apoptosis and improving the efficiency of organs.

The objective of our experiment was to investigate the effect of Epo on fibrosis and apoptosis in experimental model of CP. During the experiment we observed characteristic morphological features of the early phase of CP in the form of interstitial oedema, vacuolisation, and the presence of inflammatory mass. Interstitial and ductal fibrosis were also noticed. Animals were decapitated $24 \mathrm{~h}$ after receiving a last dose of cerulein, due to the potential reversibility of the lesions. The observed changes were accompanied by a slight increase in the activity of MMPs, primarily MMP-9, and the strong expression of $\alpha$-smooth muscle actin, caspase- 3 , and the slight expression of $\mathrm{Bcl}-2$ protein. These changes are typical for cerulein-induced CP and have been described in many other publications $[56,57]$. As a result of our experiment, administration of Epo to animals with induced CP significantly reduced interstitial oedema and reduced the severity of fibrosis. Additionally, immunohistochemical reaction showed significantly lower expression of $\alpha$-smooth muscle actin and caspase- 3 , and a lack of $\mathrm{Bcl}-2$ expression. In the animals receiving the lower dose of Epo, these changes were less pronounced. Because caspase- 3 plays a key role in the activation of caspase cascade, it may suggest an important part of apoptosis in the pathogenesis of CP. This can result in inhibition of development of exocrine function failure by reducing the pancreatic acinar cell population undergoing apoptosis. However, there was no expression of caspase-9 observed. In the conducted model an initial phase of CP was reached. It must therefore be assumed that caspase- 9 is not involved in apoptosis in the early stages of the disease. At the same time, the reduced expression of muscle $\alpha$-actin (ASMA) may indicate a reduction in the number of active stellate cells of the pancreas, and thus lead to inhibition of the activation processes of degeneration of the extracellular matrix and to a reduction in the risk of increased fibrosis of the pancreas. Also very promising are the histopathological findings showing less severe inflammatory changes and fibrosis.

In conclusion, the future of therapy with recombinant human Epo and its use as a treatment of CP appears to be promising. There is increasing evidence on the therapeutic benefit of rhEpo administration. However, the insufficient amount of research and not fully understood pathogenic mechanisms of CP show the need to expand research on the presented topic, which could give hope for the future use of Epo as an effective therapy of CP.

\section{Conflict of interest}

The authors declare no conflict of interest. 


\section{References}

1. Dzieniszewski J, Jarosz M, Ciok J. Chronic pancreatitis in Warsaw. Mater Med Pol 1990; 22: 202-4.

2. Jupp J, Fine D, Johnson CD. The epidemiology and socioeconomic impact of chronic pancreatitis. Best Pract Res Clin Gastroenterol 2010; 24: 219-31.

3. Philippe L, Dominguez-Munoz E, Imrie C, et al. Epidemiology of chronic pancreatitis: burden of the disease and consequences. United European Gastroenterol J 2014; 2: 345-54.

4. Garg P, Tandon R. Survey on chronic pancreatitis in the Asia-Pacific region. J Gastroenterol Hepatol 2004; 19: 998-1004.

5. Hirota M, Shimosegawa T, Masamune A, et al. Research Committee of Intractable Pancreatic Diseases. The sixth nationwide epidemiological survey of chronic pancreatitis in Japan. Pancreatology 2012; 12: 79-84.

6. Hobbs P, Johnson W, Graham D. Management of pain in chronic pancreatitis with emphasis on exogenous pancreatic enzymes. Word J Gastrointest Pharmacol Ther 2016; 7: 370-86.

7. Ammann R. Diagnosis and menagement of chronic pancreatitis: current knowladge. Swiss Med Wkly 2006; 136: 166-74.

8. Herreros-Villanueva M, Hijona E, Banales JM, Cosme A, Bujanda L. Alcohol consumption on pancreatic diseases. World J Gastroenterol 2013; 7: 638-47.

9. Whitcomb DC. Hereditary pancreatic: new insights into acute and chronic pancreatitis. Gut 1999; 45: 31722.

10. Apte M, Pirola R, Wilson J. The fibrosis of chronic pancreatitis: new insights into the role of pancreatic stellate cells. Antioxid Redox Sign 2011; 15: 2711-22.

11. Watari N, Hotta Y, Mabuchi Y. Morphological studies on a vitamin A-storing cell and its complex with macrophage observed in mouse pancreatic tissues following excess vitamin A administration. Okajimas Folia Anat Jpn 1982; 58: 837-58.

12. Mews P, Philips P, Fahmy R, et al. Pancreatic stellate cells respond to inflammatory cytokines: potential role in chronic pancreatitis. Gut 2002; 50: 535-41.

13. Sendler M, Beyer G, Mahajan U, et al. Complement component 5 mediates development of fibrosis, via activation of stellate cells, in 2 mouse models of chronic pancreatitis. Gastroenterol 2015; 149: 765-76.

14. Apte MV, Phillips P, Fahmy R, et al. Does alcohol directly stimulate pancreatic fibrogenesis? Studies with rat pancreatic stellate cells. Gastroenterology 2000; 118: 780-94.

15. Ferdek P, Jakubowska M. Biology of pancreatic stellate cells-more than just pancreatic cancer. Pflugers Arch 2017; 469: 1039-50.

16. Omary MB, Lugea A, Lowe AW, Pandol SJ. The pancreatic stellate cell: a star on the rise in pancreatic diseases. J Clin Invest 2007; 117: 50-9.

17. Apte MV, Haber PS, Applegate T, et al. Periacinar stellate shaped cells in rat pancreas-identification, isolation, and culture. Gut 1998; 43: 128-33.

18. Olszowiec-Chlebna M, Koniarek-Maniecka A, Stelmach W, et al. Predictors of deterioration of lung function in Polish children with cystic fibrosis. Arch Med Sci 2016; 12: 402-7.

19. Ziółkowska L, Petryka J, Boruc A, Kawalec W. Comparison of echocardiography with tissue Doppler imaging and magnetic resonance imaging with delayed enhancement in the assessment of children with hypertrophic cardiomyopathy. Arch Med Sci 2017; 13: 328-36.
20. Eren Z, Gunal M, Ari E, et al. Pleiotropic and renoprotective effects of erythropoietin beta on experimental diabetic nephropathy model. Nephron 2016; 132: 292-300.

21. Woessner JF Jr. Matrix metalloproteinases and their inhibitors in connective tissue remodeling. FASEB J 1991; 5: 2145-54.

22. Panwar P, Butler GS, Jamroz A, et al. Aging-associated modifications of collagen affect its degeneration by matrix metalloproteinases. Matrix Biol 2018; 65: 30-44.

23. Leers MP, Kolgen $W$, Bjorklund $V$, et al. Immunohistochemical detection and mapping of cytokeratin 18 neoepitope exposed during early apoptosis. J Pathol 1999; 187: 547-72.

24. Krantz SB. Erythropoietin. Blood 1999; 77: 419-34.

25. Gamze U, Aysegul C, Handan M, et al. Neuroprotective effects of erythropoietin against oxidant injury following brain irradiation: an experimental study. Arch Med Sci 2016; 12: 1348-53.

26. Moore E, Bellomo R. Erythropoietin (Epo) in acute renal injury. Ann Intensive Care 2011; 1: 3.

27. Juul SE, Joyce AE, Zhao Y, Ledbetter DJ. Why is erythropoietin present in human milk? Studies of erythropoietin receptors on enterocytes of human and rat neonates. Pediatr Res 1999; 46: 263-8.

28. Depping R, Kawakami K, Ocker H, et al. Expression of the erythropoietin receptor in human heart. J. Thorac Cardiovasc Surg 2005; 130: 877-8.

29. Fenjves ES, Ochoa MS, Cabrera O, et al. Human, nonhuman primate, and rat pancreatic islets express erythropoietin receptors. Transplantation 2003; 75: 1356-60.

30. Fenjves ES, Ochoa MS, Gay-Rabinstein C, et al. Adenoviral gene transfer of erythropoietin confers cytoprotection to isolated pancreatic islets. Transplantation 2004; 77: 13-8.

31. Kutwin M, Sawosz E, Jaworski S, et al. Investigation of platinum nanoparticle properties against U87 glioblastoma multiforme. Arch Med Sci 2017; 13: 1322-34.

32. Malik S, Mukhopadhyay A, Maulik U. Integrated statistical and rule-mining techniques for DNA methylation and gene expression data analysis. JAISCR 2013; 3: 101-15.

33. Bandyopadhyay S, Mallik S, Mukhopadhyay A. A survey and comparative study of statistical tests for identifying differential expression from microarray data. IEEE/ACM Trans Comput Biol Bioinform 2014; 11: 95-115.

34. Satoh A, Satoh K, Masamune A, Yamagiwa T, Shimosegawa T. Activation of adenosine A2a receptor pathway reduces leukocyte infiltration but enhances edema formation in rat caerulein pancreatitis. Pancreas 2002; 24: 75-82.

35. Rathod DB, Salahudeen AK. Nonerythropoietic properties of erythropoietin: implication for tissue protection. J Investig Med 2011; 59: 1083-5.

36. Saraste A, Pulkki K, Kallajoki M, Henriksen K, Parvinen M, Voipio-Pulkki LM. Apoptosis in human acute myocardial infarction. Circulation 1997; 95: 320-3.

37. Narula J, Haider N, Virmani R, et al. Apoptosis in myocytes in end-stage heart failure. N Engl J Med 1996; 335: 1182-9.

38. Cai Z, Manalo DJ, Wei G, et al. Hearts from rodents exposed to intermittent hypoxia or erythropoietin are protected against ischemia - reperfusion injury. Circulation 2003; 108: 79-85.

39. Ruscher K, Freyer D, Karsch M, et al. Erythropoietin is a paracrine mediator of ischemic tolerance in the brain: evidence from an in vitro model. J Neurosci 2002; 22: 10291-301.

40. Gonzalez FF, Abel R, Almli CR, Mu D, Wendland M, Ferriero DM. Erythropoietin sustains cognitive function and 
brain volume after neonatal stroke. Dev Neurosci 2009; 31: 403-11.

41. Jerndal M, Forsberg K, Sena ES, et al. A systematic review and meta-analysis of erythropoietin in experimental stroke. J Cereb Blood Flow Meta 2010; 30: 961-8.

42. Ugurluer G, Cebi A, Mert H, et al. Neuroprotective effects of erythropoietin against oxidant injury following brain irradiation: an experimental study. Arch Med Sci 2016; 6: 1348-53.

43. Bogoyevitch MA. An update on the cardiac effects of erythropoietin cardioprotection by erythropoietin and the lessons learnt from studies in neuroprotection. Cardiovascular Res 2004; 63: 208-16.

44. Ehrenreich H, Hasselblatt M, Dembowski C, et al. Erythropoietin therapy for acute stroke is both safe and beneficial. Mol Med 2002; 8: 495-505.

45. Ehrenreich H, Weissenborn K, Prange H, et al. Recombinant human erythropoietin in the treatment of acute ischemic stroke. Stroke 2009; 40: 647-56.

46. Sepodes B, Maio R, Pinto R, et al. Recombinant human erythropoietin protects the liver from hepatic ischemiareperfusion injury in the rat. Transpl Int 2006; 19: 919-26.

47. Shmeding M, Hunold G, Ariyakhagorn V, et al. Erythropoietin reduces ischemia-reperfusion injuring in the rat liver. Eur Surg Res 2007; 39: 189-97.

48. Mądro A, Kurzepa J, Czechowska G, Stomka M, Celiński K, Szymonik-Lesiuk S. Erythropoietin inhibits liver gelatinases during galactosamine-induced hepatic damage in rats. Pharmacol Rep 2009; 61: 917-23.

49. Ucan BH, Irkorucu O, Cakmak GK, et al. Erythropoietin: a possible cytoprotective cytokine in acute necrotizing pancreatitis. J Hepatobiliary Pancreat Surg 2009; 16: 530-7.

50. Craig KJ, Williams JD, Riley SR, et al. Anemia and diabetes in the absence of nephropathy. Diabetes Care 2005 28: 1118-23.

51. Thomas MC. The high prevalence of anemia in diabetes is linked to functional erythropoietin deficiency. Semin Nephrol 2006; 26: 275-82.

52. Choi D, Schroer SA, Lu SY, et al. Erythropoirtin protects against diabetes through direct effect on pancreatic beta cells. J Exp Med 2010; 207: 2831-42.

53. Eren Z, Gunal M, Coban J, et al. Pleiotropic and renoprotective effects of erythropoietin beta on experimental diabetic nephropathy model. Exp Nephrol 2016; 132: 292-300.

54. Chen X, Gou Z, Wang P, Xu M. Erythropoietin modulates imbalance of matrix metalloproteinase- 2 and tissue inhibitor of metalloproteinase-2 in doxorubicin-induced cardiotoxicity. Heart Lung Circ 2014; 23: 772-7.

55. Pawlak K, Pawlak D, Myśliwiec M. Long-term erythropoietin therapy does not affect metalloproteinases and their inhibitor levels, oxidative stress and inflammation in hemodialyzed patients. Am J Nephrol 2007; 27: 221-5.

56. Hyun JJ, Lee HS. Experimental models of pancreatitis. Clin Endosc 2014; 47: 212-16.

57. Aghdassi A, Mayerle J, Christochowitz S, Weiss FU, Sendler M, Lerch MM. Animal models for investigating chronic pancreatitis. Fibrogenesis Tissue Repair 2011; 4: 26. 